Article

\title{
Ball trajectories and probability of scoring a goal in elite male goalball throws
}

\author{
Rafael Fujita1 ${ }^{1}$ Otávio Furtado² and Márcio Morato ${ }^{3 *}$ \\ Received: $7^{\text {th }}$ January 2020; Accepted: $4^{\text {th }}$ January 2021; Published: $19^{\text {th }}$ April 2021
}

\begin{abstract}
Goalball court can be divided into six sectors, each measuring $1.5 \mathrm{~m}$ in width. The sectors are used for analysing the game. To shed light on spatial factors that may influence offensive and defensive success in goalball, we analysed the throwing frequency and attack efficacy with different ball trajectories in elite male goalball attacks. We determined the origin and target sectors (sector 1 on the farright goalpost of the court and sector 6 to the left goalpost to goalpost) of 7949 throws from 49 matches played at Paralympic Games and World Championships. The reliability ranged from .82 to 1.00 using the Kappa index. Our findings showed that attackers frequently used the side sectors as the origin and threw the majority of balls at either the target sectors in front of them or the direct neighbour sectors, justifying a team's defensive movement as a block towards the opponent's attack origin. Throw trajectory efficacy originating from sector 2 (the second far-right of the goalpost) was not equally distributed among the different target sectors. In particular, balls directed to sector 3 presented an overall higher likelihood of success (8.4\%). Additionally, ball trajectory efficacy from sector 1 to 3 was statistically different between winners vs. losers $(5.4 \%$ vs. $0.5 \%, p=.02)$ and best vs. worst teams $12.4 \%$ vs. $2.2 \%, \mathrm{p}=.02$ ). This knowledge has the potential to help goalball coaches to structure specific offensive and defensive training programs.
\end{abstract}

Keywords: visual impairment; performance analysis; Paralympics; tactical evaluation; patterns of play

\section{Introduction}

Goalball is a team sport played by athletes with visual impairments. According to the sport classification system, blind athletes (i.e., B1) or those with low vision (i.e., B2 and B3) are eligible to compete in events regulated by the International Blind Sports Federation (IBSA) or the International Paralympic Committee (Çolak, Bamaç, Aydin, Meriç, \& Özbek, 2004; Furtado, Morato, Potenza, \& Gutierrez, 2016). Regardless of the athlete's classification level, each team has three players on court. Contrasting with other Paralympic team sports, goalball allows more than one level of disability and does not consider the total number of classification points on the court, as in five-a-side football and wheelchair rugby, respectively (Altmann, Van Limbeek, Hart, \& Vanlandewijck, 2014; Tweedy \& Vanlandewijck, 2011). To minimize the benefit of any residual vision, all players wear eyeshades (Bednarczuk et al., 2017; Gulick \& Malone, 2011).

Positioned on each end of a volleyball court (i.e., $18 \mathrm{~m}$ x $9 \mathrm{~m}$ ), teams are composed of one centre and two wing players (Monezi et al., 2019). Performing regular attacks during play, teams demonstrate fast and precise ball control, prepare the intended strategy, and execute the throw. Ball control precedes each attack and starts after ball defence, official 
time outs (i.e., goals, court repair, noise), or when the ball is dropped by a referee or by a goal judge back into play. Attack preparation occurs with one player or multiple players being involved in the offensive situation (Morato, Furtado, Gamero, Magalhães, \& Almeida, 2017; Morato, Gomes, \& Almeida, 2012). Regarding the act of throwing, attackers often move three or four steps forward, either linearly (frontal throw) or rotationally (spin throw) (Bowerman, Davis, Ford, \& Nichols, 2011), ultimately releasing the ball from the same sector where the ball was controlled or moving to another sector.

Immediately after throwing the ball, the team starts the defensive phase, which comprises the defensive balance, throw reading, and ball blocking principles (Morato et al., 2017). In the defensive balance, athletes return to their position in the court's orientation area. This positioning rarely differs from a traditional triangular configuration, where wings sit close to the side out lines, whereas the centre player stays between them and more forward in the orientation area (Morato et al., 2012). Athletes usually find their place on court using multiple clues, such as the goalpost, raised lines marked on the floor, an audible sound provided by a teammate, or even by relying on very accurate spatial orientation (Velten, Ugrinowitsch, Portes, Hermann, \& Bläsing, 2016). Hereafter, athletes also concentrate on listening to any auditory clues the opponent may provide, which could help to detect the location where the following throw will most likely occur (e.g., ball bell sounds, steps, throwing run-up phase). With reliable information, defenders can move slightly as a block towards the sector where the attacker's run-up begins. Finally, the chance to block the ball increases if defenders effectively anticipate the possible throw target (García-Marín \& Argudo Iturriaga, 2017) and position their body in an adequate defensive posture to intercept a flat (straight or curve) or bouncing ball (Morato, Menezes, Fonseca, \& Furtado, 2018).

The inherent characteristics of a sport designed for athletes with visual impairments makes goalball a sport with greater reliance on hearing and spatial perceptions. The athletes can rely on these perceptions, whereas sports scientists and performance coaches may attempt to quantify a multitude of game behaviours to detect causal relationships (Butterworth, O’Donoghue, \& Cropley, 2013; Molik et al., 2017; Wright, Carling, \& Collins, 2014). For example, in other sports, the analysis of ball direction to and from different court locations can differentiate team performance as well as providing relevant information about teams and influencing tactical systems (Pérez, Ordóñez, \& González, 2016; Vučković et al., 2013).

In goalball, although fast balls are more likely to score (Morato et al., 2018) and the spaces between the wings and the centre are the places with the highest goal rate (Link \& Weber, 2018), little is known about the combination between the sectors of origin and target of throws (ball trajectory) and whether different throwing trajectory strategies can influence the outcome of the game or discriminate levels between teams. For this reason, the purpose of this paper was threefold: (a) to analyse the throwing frequency and attack efficacy among ball trajectories in elite male goalball throws; (b) to compare ball trajectory frequency and efficacy between winner and loser teams; and (c) to compare ball trajectory frequency and efficacy between the best and worst teams.

\section{Materials and Methods}

\section{Data Collection Procedures}

The study was conducted according to the Declaration of Helsinki and the research project was reviewed and approved by the Human Research Ethics Committee of the Local University (Faculty of Philosophy, Sciences and Letters at Ribeirão Preto; protocol number 
20768513.3.0000.5407). Also, this study was approved by the International Paralympic Committee (IPC).

A total of 70 video recorded matches, from three Paralympic Games and one Goalball World Championships were acquired from national team coaches or from the third author's archives, when he was a coach of a national goalball team. We applied the following exclusion criteria to the sample: videos were required to depict the complete goalball court and include two halves of 12 minutes each, according to the international rules. Since we did not have videos of all of the matches performed in the competitions, in order to guarantee the variability of actions and strategies, the analysis of each team in any competition did not exceed four matches. We also excluded the analysis of a second match performed by the same teams in any given competition. Hence, 49 matches were analysed (Table 1).

Table 1. Sample descriptive characteristics

\begin{tabular}{lllll}
\hline & Matches & Teams & Throws & Goals \\
\hline Competition & & & & \\
$\quad$ Beijing 2008 Paralympic Games & 10 & 9 & 1560 & 81 \\
$\quad$ Sheffield 2010 World Championship & 17 & 14 & 2584 & 141 \\
$\quad$ London 2012 Paralympic Games & 5 & 6 & 914 & 18 \\
$\quad$ Rio 2016 Paralympic Games & 17 & 9 & 3157 & 162 \\
$\quad$ Total & 49 & 38 & 8215 & 402 \\
Excluded throws ${ }^{1}$ & & & 266 & 0 \\
Throws to be analysed & & & 7949 & 402 \\
Excluded throws & & 524 & 0 \\
Attacks to be analysed & & 7425 & 402 \\
\hline $\begin{array}{l}\text { Note' } \\
\text { excluded: Not reached defending line, O1; } \mathrm{n}=261, \mathrm{O6} ; \mathrm{n}=263 .\end{array}$
\end{tabular}

\section{Observational Protocol}

Systematic video analysis using Kinovea software (vo.8.15) was performed by two observers. To assess the performance analysis, the goalball court was divided into 6 sectors, each measuring $1.5 \mathrm{~m}$ wide with sector 1 on the far-right goalpost of the court and sector 6 to the left goalpost to goalpost. To perform the goalball match analysis, an observational protocol was adapted from Morato et al. (2017) and comprised the following set of variables: 1) Throw origin: registered as 1 to 6 depending on the court sector where the ball first touched the floor after being thrown by the attacker (Figure 1). When the ball first touched the floor outside the court, we noted its origin as $\mathrm{O} 1$ or O6 (offensive right or left side, respectively);2) Throw target: registered as 1 to 6 depending on the court sector where the defender touched the ball or the sector where the ball crossed the orientation area front line. If a 'ball out' occurred, we noted O1 or O6 (defensive right or left side, respectively) as target. When a throw resulted in a penalty, the target sector was not noted. For each throw, the combination of an origin and a target sector was defined as ball trajectory; 3) Outcome: defence (defending team blocked and controlled the ball), block out (ball crossed the court limits after being blocked by defenders), ball over (defending team blocked but did not control the ball, which returned to the opposite half of the court), out (ball went out without touching any defender), penalty (a penalty occurred during throw), or goal (ball completely crossed the goal line); 4) Match result: winner or loser; 5) Team level: best teams (teams that qualified to semi-finals) and worst teams (teams that did not qualify to semi-finals). Penalty shots were not observed as one vs. one penalty situations differ from open play situations characterized by three vs. three players (Furtado et al., 2021). 


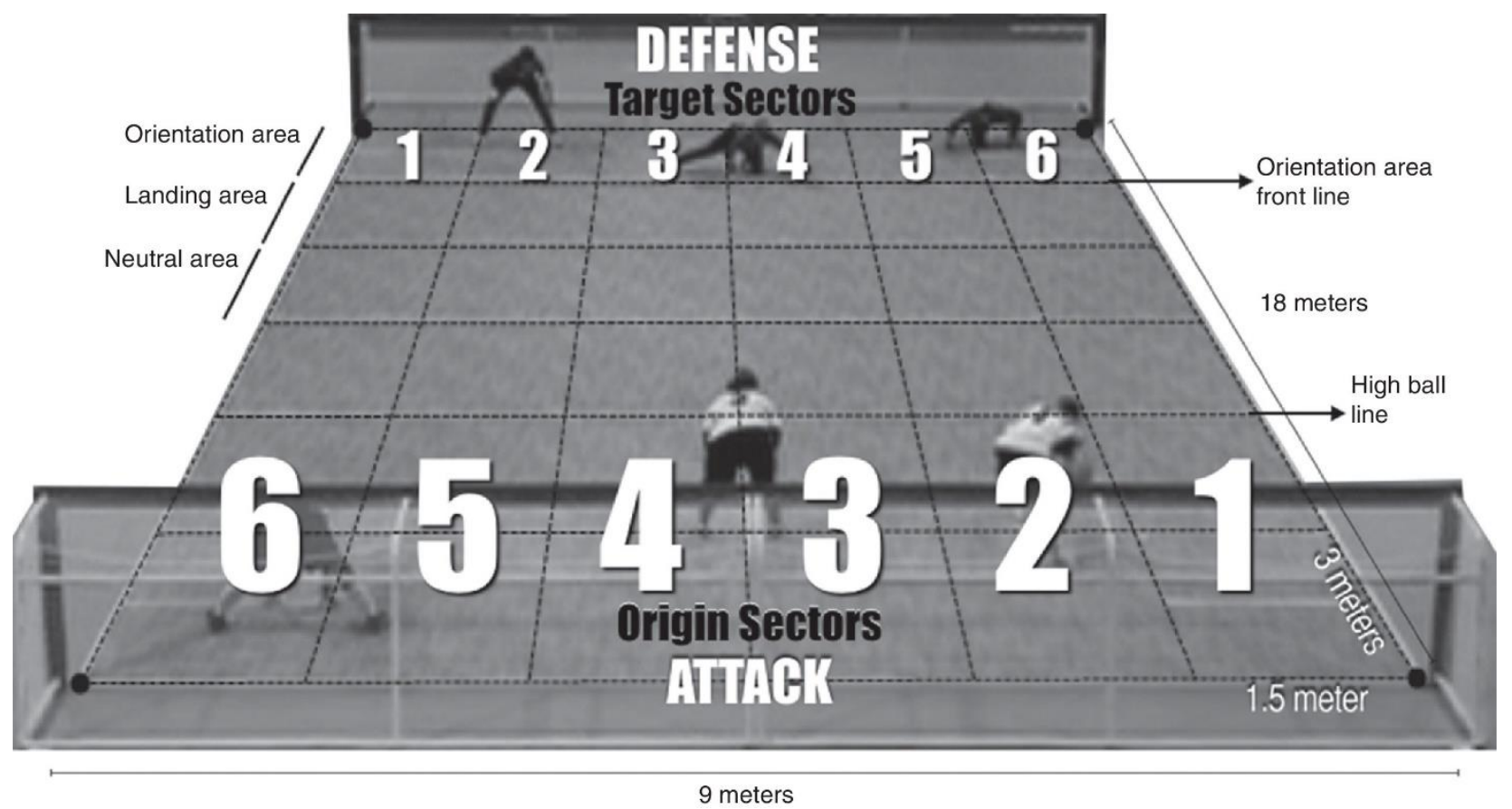

Figure 1. Illustration of the origin and target sectors in a goalball court, used with author permission from Morato, et al., 2017

\section{Reliability}

Reliability was assessed using six randomly selected matches (12,2\% of the sample). Two performance analysts observed the same matches on two different days, 15 days apart (Thomas, Nelson, \& Silverman, 2015). The intra and inter-rater Cohen's Kappa were adopted as a measure of reliability (Sainani, 2017). The intra-observer agreement for origin, target, and outcome ranged from .95 to 1.00 and the inter-observer agreement from .82 to 1.00 .

\section{Statistics}

Statistical analysis was carried out considering three parameters: the event, the match, and the team. Firstly, the unit of analysis was the event. The chi-square test was performed to examine if the frequency of throws $(\mathrm{N}=7949)$ and attack efficacy (crosstabs goal vs. nogoal) $(\mathrm{N}=7425)$ were equally distributed among origin or target sectors in general and also among trajectories (target sectors by each throw origin). The Fisher exact test was used to determine statistical significance if the expected cell frequency in at least 1 cell was $<5$. Secondly, the unit of analysis was the match $(\mathrm{N}=49)$. We calculated the percentage of occurrence and the attack efficacy for each trajectory. We used the independent samples ttest to compare the match result (winners vs. losers). Thirdly, the unit of analysis was the team $(\mathrm{N}=38)$. We ran an independent samples t-test to compare the mean percentage of occurrence and the attack efficacy for each trajectory according to the team level: best teams $(\mathrm{N}=16)$ versus worst teams $(\mathrm{N}=22)$. The level of significance was set at $\mathrm{p}<.05$ for all analysis.

\section{Results}

The frequency of throws was not equally distributed among origin, $x 2(5)=645.1, \mathrm{p}<$ .001 , or target sectors, $x 2(5)=361.6, \mathrm{p}<.001$. However, no differences were found for the attack efficacy both for origin, $x 2(5)=1.9, \mathrm{p}=.86$, or target sectors, $x 2(5)=5.4, \mathrm{p}=.37$. Considering the ball trajectories (combination of an origin and a target sector), the attack efficacy was equally distributed, except for origin $2(p=.03)$. In contrast, the frequency of throws was unevenly distributed for any origin of ball trajectory (Table 2). 
Table 2. Frequency of throws (\%) and attack efficacy (\%) according to origin sectors, target sectors, and trajectories

\begin{tabular}{|c|c|c|c|c|c|c|c|c|c|c|c|}
\hline & \multicolumn{9}{|c|}{ Target Sectors } & \multirow{2}{*}{$\chi^{2}$ Test } & \multirow{2}{*}{$\mathrm{p}$-value } \\
\hline & Total & o1 & 1 & 2 & 3 & 4 & 5 & 6 & o6 & & \\
\hline \multicolumn{12}{|c|}{ Percentage of throws $(\mathrm{N}=7949)$} \\
\hline \multicolumn{12}{|c|}{ Origin Sectors } \\
\hline 1 & 22.2 & 0.8 & 2.1 & 5.3 & 13.1 & 21.6 & 26.0 & 24.3 & 6.9 & 1037.5 & $<.001$ \\
\hline 2 & 21.3 & 1.7 & 4.8 & 14.4 & 22.6 & 20.4 & 20.4 & 12.4 & 3.4 & 1349.9 & $<.001$ \\
\hline 3 & 10.8 & 2.6 & 7.9 & 20.6 & 22.2 & 20.8 & 15.9 & 7.2 & 2.8 & 328.9 & $<.001$ \\
\hline 4 & 10.4 & 2.1 & 7.5 & 20.4 & 20.4 & 20.5 & 18.7 & 8.0 & 2.4 & 660.4 & $<.001$ \\
\hline 5 & 18.5 & 4.7 & 14.4 & 23.9 & 18.8 & 19.2 & 11.6 & 5.4 & 2.0 & 517.7 & $<.001$ \\
\hline 6 & 16.7 & 8.3 & 29.5 & 29.7 & 18.3 & 8.5 & 3.4 & 1.5 & 0.8 & 1057 & $<.001$ \\
\hline Total & 100.0 & 3.3 & 10.7 & 18.0 & 18.8 & 18.5 & 16.5 & 10.9 & 3.3 & 3.3 & $<.001$ \\
\hline \multicolumn{12}{|c|}{ Attack \% efficacy $(\mathrm{N}=7425)$} \\
\hline \multicolumn{9}{|c|}{ Origin Sectors } & & Total \% & $\mathrm{p}$-value \\
\hline 1 & 5.3 & & 0.0 & 2.2 & 6.5 & 4.5 & 7.8 & 6.3 & & 9.4 & .09 \\
\hline 2 & 5.1 & & 0.0 & 4.1 & 8.4 & 4.9 & 5.8 & 4.3 & & 12.6 & .03 \\
\hline 3 & 4.7 & & 1.5 & 4.5 & 7.4 & 5.1 & 5.1 & 3.2 & & 4.5 & .49 \\
\hline 4 & 4.5 & & 4.8 & 5.9 & 4.7 & 8.2 & 1.9 & 0.0 & & 11 & .05 \\
\hline 5 & 5 & & 6.1 & 7.4 & 4.3 & 6.0 & 4.1 & 1.3 & & 6.8 & .23 \\
\hline 6 & 4.5 & & 4.8 & 6.8 & 4.1 & 3.5 & 2.2 & 5.0 & & 4.3 & .50 \\
\hline Total & 4.9 & & 4.2 & 5.8 & 6.1 & 5.3 & 5.6 & 4.6 & & 5.4 & .37 \\
\hline
\end{tabular}

Note: in some cases, not exactly $100 \%$ due to rounding.

When comparing the mean throw trajectories according to match result, we found that winners threw more than losers from origin sector 1 to target sector 1 and from 2 to 5 , whereas losers threw more from 1 to 6 and from 2 to 4 (Figure 2).

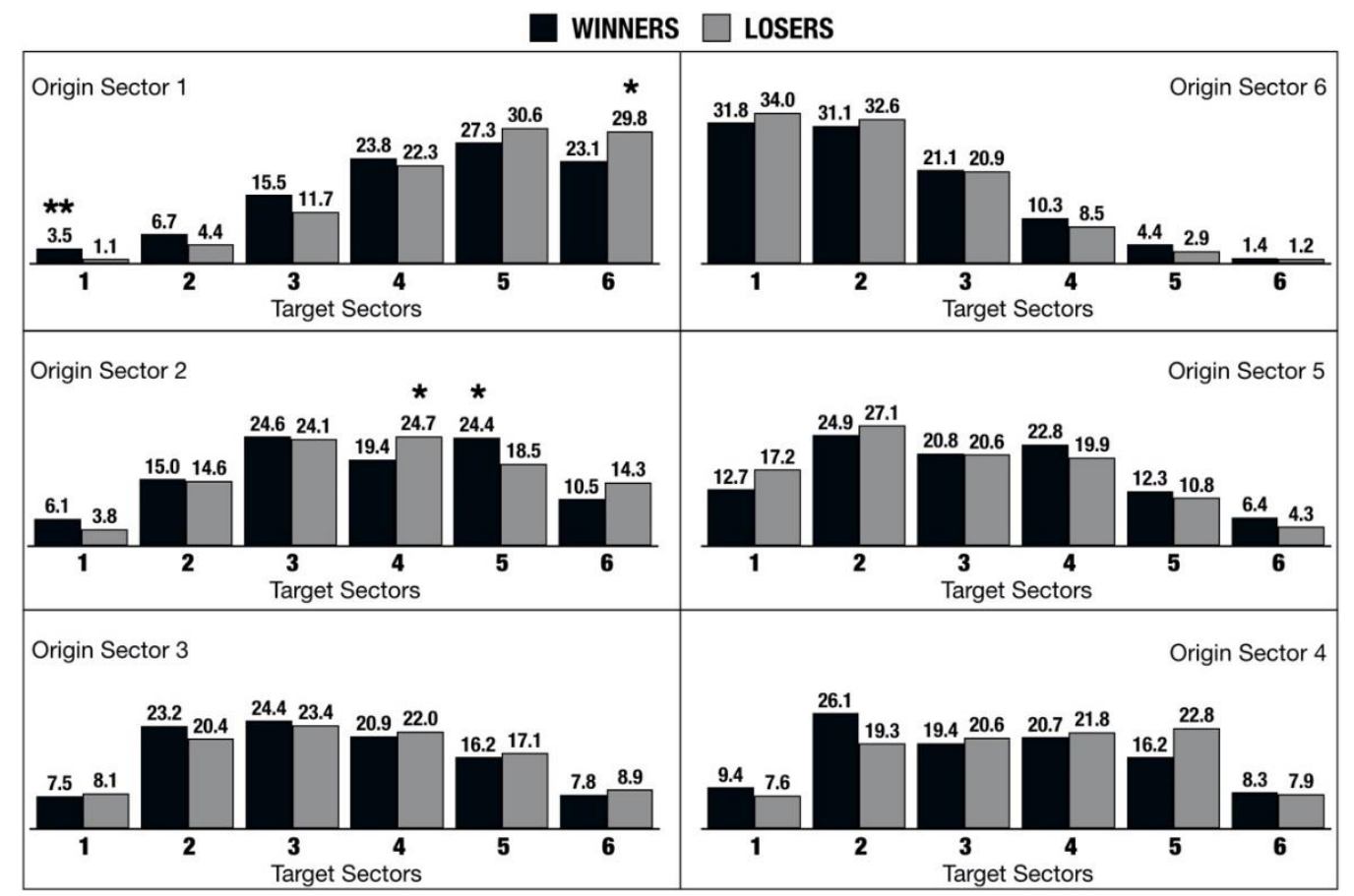

Figure 2. Comparison of mean percentage of throws for winner vs. loser. ${ }^{*} \mathrm{p}<.05 ;{ }^{* *} \mathrm{p}<.01{ }^{* * *}$ $\mathrm{p}<$.001. Note: in some cases, not exactly $100 \%$ due to rounding. 
When comparing the mean attack efficacy among the throw trajectories, winners showed better efficacy from origin 1 to target 3 (Figure 3).



Figure 3. Comparison of mean attack efficacy for winners vs. losers. ${ }^{*} \mathrm{p}<.05 ;{ }^{* *} \mathrm{p}<.01{ }^{* * *} \mathrm{p}<.001$.

Note: in some cases, not exactly $100 \%$ due to rounding.

When comparing the mean throw trajectories according to team level we found that the best teams threw more from origin sector 2 to target sector 1 and from origin 3 to sector 4 than the other teams (Figure 4).

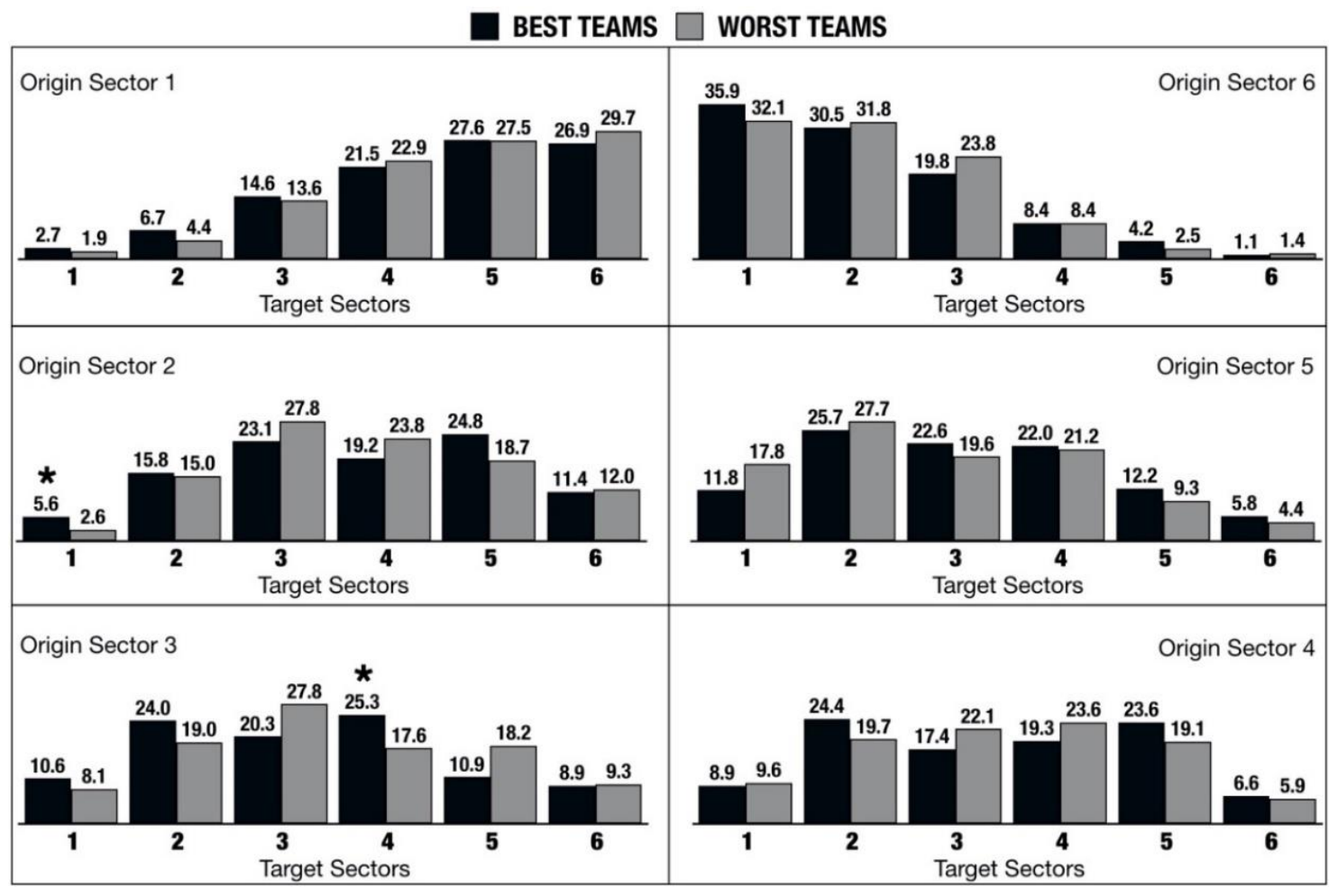

Figure 4. Comparison of mean percentage of throws for best teams vs. worst teams. ${ }^{*} \mathrm{p}<.05 ;{ }^{* *} \mathrm{p}<$ $.011^{* * *} \mathrm{p}<.001$. Note: in some cases, not exactly $100 \%$ due to rounding. 
When comparing the mean attack efficacy among the throw trajectories, the best teams showed better efficacy from origin 1 to target 3 and from origin 5 to sector 3 (Figure 5 ).

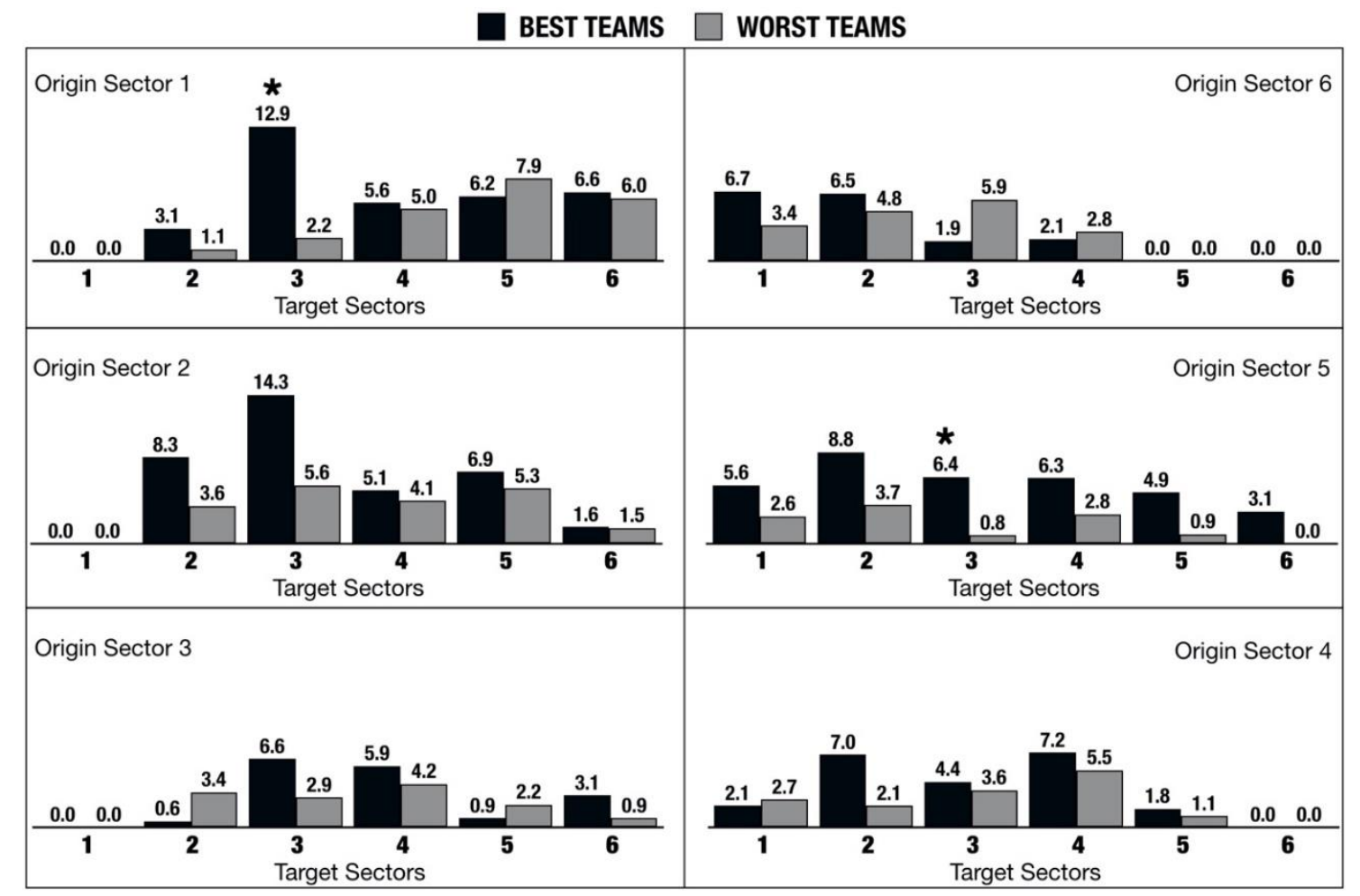

Figure 5. Comparison of mean attack efficacy for best teams vs. worst teams. ${ }^{*} \mathrm{p}<.05 ;{ }^{* *} \mathrm{p}<.01{ }^{* * *}$ $\mathrm{p}<.001$. Note: in some cases, not exactly $100 \%$ due to rounding.

\section{Discussion}

In this study we compared the origin and target throwing frequency and attack efficacy in elite male goalball. Specifically, we analysed the throw trajectories that could discriminate winners from losers and the best from worst teams based on data from three Paralympic Games and one World Championships. Our data showed that a higher frequency of throws originated from the lateral sectors (i.e., 1, 2, 5, and 6) and are, more often, directed to the central sectors of the court (i.e., 2 to 5). The efficacy of throw trajectories which originated from origin sector 2 was not equally distributed among the different target sectors, particularly, balls directed to sector 3 presented an overall higher likelihood of success (5.4\%). Finally, another significant finding refers to the ball trajectory efficacy from origin 1 to sector 3 , which was statistically different between winners vs. losers (8.4\% vs. $0.5 \%$ ) and best vs. worst teams (12.4\% vs. $2.2 \%)$.

Overall, the wing sectors were the most common throw origins when compared to more central sectors. In goalball, wing players have been regarded as attackers, performing most of the throws (85\%) and covering longer distances than centres, whereas centre players have been deemed to be more responsible for the defensive role (Monezi et al., 2019). In the orientation area, centres are often positioned more forward compared to wings and serve as front-line defence, moving sideways to block the coming ball. After a ball defence, centre players tend to pass to wings. Centres often provide auditory clues to aid attacker's spatial orientation on court, either during the run-up phase or after ball release. Thus, wings can quickly return to their defending position, transitioning to the following defensive balance principle as soon as possible (Morato et al., 2012). It has been shown that goalball athletes who are blind are better defenders than those with low vision, which explains the higher likelihood of finding B1 athletes in the centre position (Molik et al., 2015). Nonetheless, more functional spatial organization based on auditory information appears to be related to 
training and sport demands and can be developed by athletes with any visual classification (Velten et al., 2016).

To defend the $9 \mathrm{~m}$ width of their own goal, teams have the full engagement of the three athletes. Male goalball athletes who played in London 2012 had an average of $2.39 \mathrm{~m}$ of body length in the defensive position (Molik et al., 2015), leaving approximately $2 \mathrm{~m}$ to be covered by the defenders if they only laid on the floor in a straight-line position. Our results showed that longer ball trajectories were less frequent and also less likely to score a goal. For example, shots from origin sectors 1 and 2 to the target sector 1 and from 5 and 6 towards sector 6 had a total of 301 throws and only two goals scored (0.7\% attack efficacy). Thus, it is important for defenders to move as a block towards the opponent's throwing side, similar to volleyball blockers (Ficklin, Lund, \& Schipper, 2014). This strategy can reduce the need to cover an area as wide as one court sector $(1.5 \mathrm{~m})$, which could save the athletes' energy through the game. Nonetheless, the defender's auditory and spatial orientation must be trained to develop an ability to detect an attacker's origin sector and the place where they should be positioned accordingly (Schinazi, Thrash, \& Chebat, 2016; Velten et al., 2016). In this sense, adequate team communication during the game plays a major role in athletes moving synchronically to the same side.

To move towards the throw origin, defenders may use the raised lines, the ball noise, and also any noise made during the thrower run-up (Morato et al., 2012). As a counter strategy, attackers may attempt to make no noise or mislead the opponent by moving to another origin sector quietly, changing direction during a throw, handing the ball as quietly as possible to a teammate, or even by simulating the attacker run-up phase by making purposeful noise allowed by the sport rules (Morato et al., 2017). As shown by Link and Weber (2018) athletes often direct their throws to the gap between the wing and centre players. Different from our methods, Link and Weber divided the orientation area into 9 sectors of one meter (left side of the court: sectors A, B, C and D; middle sector E; and right side of the court: sectors D, C, B, and A). The authors showed that in elite goalball, irrespective of sex and without consideration for origin sectors, the target sectors $\mathrm{C}$ and $\mathrm{D}$ received most balls. Thus, it appears that athletes try to attack the gaps between the defenders.

As we found a significant difference in the likelihood of scoring a goal in only one ball trajectory (i.e., 1 to 3 ) in the comparison between winners vs. losers and best vs. worst teams, we believe that attack strategies may serve to increase the chances of scoring a goal and deserve to be further investigated. Indeed, as all athletes are blindfolded, shooting a ball exactly into a specific spot is not an easy task, however, since we are dealing with elite athletes, spending some time training this skill seems to be feasible and worth the time. Furthermore, if we consider that the best attackers have a B2 or B3 sport classification (Molik et al., 2015), their residual vision could be a valuable asset during the throw training.

Considering ball trajectory, based on our findings, athletes should refrain from shooting extreme diagonal balls (i.e., 1 to $1 ; 2$ to $1 ; 6$ to $6 ; 5$ to 6 ) as it takes longer for the ball to reach the opposite orientation area and, consequently, provides more time for defenders to determine ball trajectory and block it. In this sense, Morato et al. (2018) showed that reducing ball time was associated with an increase in the attack efficacy. Short trajectories (parallel and short diagonal) reached the opposite area earlier and were the most used by athletes (36\% and 26\%, respectively). In this sense, our results are in accordance with Link and Weber (2018) who showed higher incidence rates of straight shots $(+127.9 \%)$ against diagonal shots. Straight shots were also $25.6 \%$ more successful than diagonal shots.

Indeed, according to our data, longer trajectories have more chance to go out over the sideline ( $80 \%$ on average - considering these trajectories 1 to $1 ; 2$ to $1 ; 6$ to $6 ; 5$ to 6 together), 
either without touching any defender (49\%) or by being blocked out (31\%). This provides defenders with an advantage in the transition to the following attack, as the ball will be dropped into play by a referee. Thus, the team will have longer to execute the most convenient attack strategy without the time pressure due to the defensive ten second rule. According to goalball rules, a team has ten seconds to ensure the ball crosses the court centre line after it goes out or first touches any defender (IBSA, 2019). However, if extreme diagonal balls are detected to be efficient against a specific team, it may be worth the risk, having no reason to rule out their use (García-Tormo, Vaquera, \& Morante Rábago, 2015). Additionally, in some critical moments and according to the opponent characteristics, athletes or coaches may choose among trajectories which, although with a significant difference, had a good attack efficacy (i.e., 1 to $5 ; 2$ to $3 ; 3$ to $3 ; 4$ to $4 ; 5$ to $2 ; 6$ to 2 ).

\section{Conclusions}

This study provides insights into the throwing frequency and attack efficacy from several court sectors in elite male goalball. Our results demonstrated that the right (1 and 2) and left (5 and 6) sectors were commonly used as origin throw sectors, whereas the central sectors (3 and 4) received the majority of attacks, in general. Considering the ball trajectories (origin and target combinations), attackers threw most balls at the target sectors in front of them or neighbouring sectors. This justifies the team movement as a block towards the opponent attack origin. Furthermore, shooting extreme diagonal ball trajectories (i.e., 1 to $1 ; 2$ to $1 ; 6$ to $6 ; 5$ to 6 ) should be avoided, due to the low attack efficacy and also because these trajectories usually go out over the side-line. Knowledge of the spatial aspects of goalball throws enables coaches not only to structure specific offensive and defensive training programs, but also to select players according to their ability to perform determined roles on court.

\section{Perspectives}

From our practical experience and as it seems logical in other sports, the availability of time to play a shot tends to facilitate the decision-making process of athletes (Vučković et al., 2013). Also, providing instructions with augmented feedback information to the goalball players can improve their performance accuracy (Shimony, Lidor, \& Ziv, 2020). In goalball, when a team has close to ten seconds of ball possession, more elaborated attacks can be planned and executed, including a quiet change of origin sector before a throw, ball pass, or set piece. We often perceive that counterattacks, that is, directing the throw to where the previous shot was performed, also tend to increase the likelihood of scoring. However, these situations still deserve further investigation, as well as the effect of different ball types (i.e., flat, bouncing, and curve) and ball speed on the attack efficacy in goalball.

\footnotetext{
Author affiliations:

1 University of São Paulo, School of Physical Education and Sport of Ribeirão Preto, Brazil; rafakirafujita@gmail.com / rafael.akira.fujita@usp.br

2 University of São Paulo, School of Physical Education and Sport, Brazil; otaviofurtado@usp.br

3 University of São Paulo, School of Physical Education and Sport of Ribeirão Preto, Brazil; mpmorato@usp.br

* Correspondence: mpmorato@usp.br; Tel.: +55 1633150349
}

Author Contributions: Conceptualization, RF, MM, OF; Methodology, RF, MM, OF; Formal Analysis, RF, MM; Writing-Review \& Editing, RF, MM, OF

Funding: This research was funded by the São Paulo Research Foundation (FAPESP) grants \#2014/o8360-9 and \#2015/19587-7, and by the Coordenação de Aperfeiçoamento de Pessoal de Nível Superior (CAPES) finance code 001.

Acknowledgments: This study was approved by the International Paralympic Committee (IPC) Sports Science Working Group.

Conflicts of Interest: The authors declare no conflict of interest. 


\section{References}

Altmann, V. C., Van Limbeek, J., Hart, A. L., \& Vanlandewijck, Y. C. (2014). Improvement of the Classification System for Wheelchair Rugby: Athlete Priorities. Adapted Physical Activity Quarterly, 31(4), 377-389. https://doi.org/10.1123/apaq.2013-0064

Bednarczuk, G., Molik, B., Morgulec-Adamowicz, N., Kosmol, A., Wiszomirska, I., Rutkowska, I., \& Perkowski, K. (2017). Static balance of visually impaired paralympic goalball players. International Journal of Sports Science \& Coaching, 12(5), 611-617. https://doi.org/10.1177/1747954117727791

Bowerman, S., Davis, R., Ford, S., \& Nichols, D. (2011). Phases of movement of goalball throw related to ball velocity. Insight: Research and Practice in Visual Impairment and Blindness, 4, 153-159.

Butterworth, A., O’Donoghue, P., \& Cropley, B. (2013). Performance profiling in sports coaching: a review. International Journal of Performance Analysis in Sport, 13(3), 572-593. https://doi.org/10.1080/24748668.2013.11868672

Çolak, T., Bamaç, B., Aydin, M., Meriç, B., \& Özbek, A. (2004). Physical fitness levels of blind and visually impaired goalball team players. Isokinetics and Exercise Science, 12(4), 247-252. https://doi.org/10.3233/IES-2004-0182

Ficklin, T., Lund, R., \& Schipper, M. (2014). A comparison of jump height, takeoff velocities, and blocking coverage in the swing and traditional volleyball blocking techniques. Journal of Sports Science \& Medicine, 13(1), 78-83. Retrieved from http://www.ncbi.nlm.nih.gov/pubmed/24570609

Furtado, O. L. P., Morato, M. P., Potenza, M., \& Gutierrez, G. L. (2016). Health-related physical fitness among young goalball players with visual impairments. Journal of Visual Impairment \& Blindness, 110(4), 257-267. https://doi.org/10.1177/0145482X1611000405

Furtado, O., Häyrinen, M., Alves, I., Travitzki, L., \& Morato, M. P. (2021). Factors Associated With Penalty Outcome on Male Elite Goalball. Adapted physical activity quarterly : APAQ, 1-13. Advance online publication. https://doi.org/10.1123/apaq.2020-0117

García-Marín, P., \& Argudo Iturriaga, F. M. (2017). Water polo: technical and tactical shot indicators between winners and losers according to the final score of the game. International Journal of Performance Analysis in Sport, 17(3), 334-349. https://doi.org/10.1080/24748668.2017.1339258

García-Tormo, J. V., Vaquera, A., \& Morante Rábago, J. (2015). Methodological proposal for the quantification and analysis of the level of risk assumed in volleyball service execution in female high-level competition. Journal of Physical Education and Sport, 15, 108-113. https://doi.org/10.7752/jpes.2015.01018

Gulick, D. T., \& Malone, L. A. (2011). Field test for measuring aerobic capacity in paralympic goalball athletes. International Journal of Athletic Therapy \& Training, 16(5), 22-25. https://doi.org/10.1123/ijatt.16.5.22

IBSA. (2019). IBSA Goalball Rules and Regulations. https://www.ibsasport.org/sports/goalball/rules/

Link, D., \& Weber, C. (2018). Finding the gap: An empirical study of the most effective shots in elite goalball. PLOS ONE, 13(4), e0196679. https://doi.org/10.1371/journal.pone.0196679

Molik, B., Morgulec-Adamowicz, N., Kosmol, A., Perkowski, K., Bednarczuk, G., Skowroński, W., ... Szyman, R. J. (2015). Game Performance Evaluation in Male Goalball Players. Journal of Human Kinetics, 48(1), 43-51. https://doi.org/10.1515/hukin-2015-0090

Molik, B., Morgulec-Adamowicz, N., Marszałek, J., Kosmol, A., Rutkowska, I., Jakubicka, A., ... Gómez, M.-Á. (2017). Evaluation of game performance in elite male sitting volleyball players. Adapted Physical Activity Quarterly, 34(2), 104-124. https://doi.org/10.1123/apaq.2015-0028

Monezi, L. A., Magalhães, T. P., Morato, M. P., Mercadante, L. A., Furtado, O. L. P. da C., \& Misuta, M. S. (2019). Time-motion analysis of goalball players in attacks: differences of 
the player positions and the throwing techniques. Sports Biomechanics, 18(5), 470481. https://doi.org/10.1080/14763141.2018.1433871

Morato, M. P., Furtado, O. L. P. da C., Gamero, D. H., Magalhães, T. P., \& Almeida, J. J. G. de. (2017). Development and evaluation of an observational system for goalball match analysis. Revista Brasileira de Ciências Do Esporte, 39(4), 398-407. https://doi.org/10.1016/j.rbce.2016.08.002

Morato, M. P., Gomes, M. S. P., \& Almeida, J. J. G. de. (2012). Os processos autoorganizacionais do goalball. [The self-organizations processes of goalball] Revista Brasileira de Ciências Do Esporte, 34(3), 741-760. https://doi.org/10.1590/So10132892012000300015

Morato, M. P., Menezes, R. P., Fonseca, S., \& Furtado, O. L. P. da C. (2018). Faster balls increase the probability of scoring a goal in female and male elite goalball. Revista Brasileira de Ciências Do Esporte, 4O(4), 427-434. https://doi.org/10.1016/j.rbce.2018.03.027

Sainani, K. L. (2017). Reliability Statistics. $P M \& R, 9(6), 622-628$. https://doi.org/10.1016/j.pmrj.2017.05.001

Schinazi, V. R., Thrash, T., \& Chebat, D.-R. (2016). Spatial navigation by congenitally blind individuals. Wiley Interdisciplinary Reviews: Cognitive Science, 7(1), 37-58. https://doi.org/10.1002/wcs.1375

Shimony, N., Lidor, R., \& Ziv, G. (2020). The effectiveness of bandwidth knowledge of results on a throwing task in goalball players with visual impairments. European Journal of Adapted Physical Activity, 13(2), 13. https://doi.org/10.5507/euj.2020.009

Thomas, J. R., Nelson, J. K., \& Silverman, S. J. (2015). Research methods in physical activity. Champaign, IL: Human Kinetics.

Tweedy, S. M., \& Vanlandewijck, Y. C. (2011). International Paralympic Committee position stand--background and scientific principles of classification in Paralympic sport. British Journal of Sports Medicine, 45(4), 259-269. https://doi.org/10.1136/bjsm.2009.065060

Velten, M. C. C., Ugrinowitsch, H., Portes, L. L., Hermann, T., \& Bläsing, B. (2016). Auditory spatial concepts in blind football experts. Psychology of Sport and Exercise, 22, 218-228. https://doi.org/10.1016/j.psychsport.2015.08.010

Vučković, G., James, N., Hughes, M., Murray, S., Sporiš, G., \& Perš, J. (2013). The effect of court location and available time on the tactical shot selection of elite squash players. Journal of Sports Science \& Medicine, 12(1), 66-73. PMID: 24149727; PMCID: PMC3761750.

Wright, C., Carling, C., \& Collins, D. (2014). The wider context of performance analysis and it application in the football coaching process. International Journal of Performance Analysis in Sport, 14(3), 709-733. https://doi.org/10.1080/24748668.2014.11868753 (C) 2021 by the authors. Submitted for possible open access publication under the terms and conditions of the Creative Commons Attribution (CC BY) license (http://creativecommons.org/licenses/by/4.o/). 